\title{
Original article \\ Environmental and Nutritional Determinants of Diarrhoea Disease Among Children Under Five Years in Rwanda: A Secondary Data Analysis of the Rwanda Demographic and Health Survey 2014-15
}

\author{
Christian J. Ishimwe ${ }^{1 *}$, Erigene Rutayisire ${ }^{2}$, Onesmus Marete ${ }^{2}$ \\ ${ }^{1}$ Planning Division, Rwanda Biomedical Center, Kigali, Rwanda \\ ${ }^{2}$ Mount Kenya University, Kigali, Rwanda \\ *Corresponding author: Christian J. Ishimwe, Planning Division, Rwanda \\ Biomedical Center, P.O. Box 7162 Kigali, Rwanda. Email: \\ juleschristianishi@gmail.com.
}

\begin{abstract}
\section{Background}

Diarrhoea remains one of the leading of causes of deaths in children under five years old globally. Children under five years are more vulnerable to diarrhea especially those from low and middle countries. The aim of this study was to explore the environmental and nuttitional factors associated with diarrhea among children underfive years in Rwanda.
\end{abstract}

\section{Methods}

A secondary data analysis of the Rwanda Demographic and Heralth Survey 2014-2015 (RDHS 2014-2015) was used. A total sample of 7,558 children under five years old was included. The data were analysed using Stata 13. Bivariate with Chi-square test and multivariable logistic regression analysis were performed to assess the relashionship of factors associsted with diarreha. A 95\% confidence interval and a significance level of 0.05 were set. Results

Two environmental factors (Source of drinking water and shared toilets facilities with other households) were associated with child diarrhea. Pvalues: 0.029, OR:1.79, CI [1.06-3.01]; 0.019, OR:1.26, CI: [1.04-1.53] respectively. None of the selected nutritional factors was associated with childhood diarrhea.

\section{Conclusion}

Based on the findings, drinking borehole water and shared toilet facilities were associated with diarrhea. The study therefore recommends the provision of potable water and supporting/enabling the households to own toilets.

Rwanda J Med Health Sci 2020;3(3):280-290

Keywords: Under five children, environmental and nutritional determinants, diarrhea, Rwanda 


\section{Background}

Diarrhoea is one of the leading causes of death in children underfive old globally, and it is responsible for an estimated 525 000 deaths annually. [1,2] Diarrhea causes nearly 1.7 billion cases every year, and high estimates were documented mainly in low and middle income countries (LMICs). Diarrhea commonly affect children especially those living in the areas with poor hygiene and sanitation and with limited access to safe water. It is estimated that 1.5 to 2.2 million people die each year from diarrhea and its related diseases and high vulnerability occur particularly in young children in their first two years of live. $[3,4]$

Diarrhoea is the passage of three or more loose or watery stools within a day or unusual frequency of diarrhea episodes.[5]It can be prevented through a community led total sanitation and hygiene interventions. Preventive measures to reduce exposure to enteric pathogens responsible for diarrheal diseases can include improved quality drinking and cooking water, hand-washing practice, safe storage of food, and sanitary disposal of fecal waste.[6]

Some initiatives have been established to lessen the burden of diarrhea, including notably a Global Action Plan for Pneumonia and Diarrhoea (GAPPD) with goals to ensure child access to appropriate preventive and treatment services.[7] However, diarrhea is still a high burden disease and it results from a complex interaction of environmental and food, sanitation and hygiene. $[8,9]$ The global burden of diseases, injuries and risk factors study estimated that diarrhea was responsible for an estimated 330000 deaths among children under five years of age in 2015.[7,10]

Children younger than five years old in LMICs in South Asia and Sub-Saharan Africa experience an average of three episodes of diarrhea per year. Incidence rates vary but are higher in children in low income countries, and highest in Sub-Saharan Africa where a child can experience three diarrhea episodes per year. An estimated 526,000 under five child deaths due to diarrhea occurred in 2015, representing a fifty-eight percent reduction from 2000 to 2015.[6] The 2014-15 Rwanda Demographic and Health Survey reported that $12 \%$ of children underfive years old had diarrhea within the two weeks preceeding the survey [11] but factors behind diarrhea occurance were not reported. The present study therefore explored environmental and nutritional determinants of diarrhoea among children under 5 years in based on data from the Rwanda National survey. 


\section{Methods}

\section{Design and setting}

A secondary data analysis was used to explore factors associated with diarrhea among children under five years old. This study used the data from the National Demographic and Health Survey conducted by the 2014-2015 RDHS.

\section{Population}

The current study has used a total of 7,558 children under five years included in the survey and whose information was collected by the RDHS.[11]

\section{Sample size and sampling strategy}

The study used a sample from the Rwanda Demographic and Health Survey (RDHS) conducted by the National Institute of Statistics of Rwanda (NISR) in November 2014April 2015.The 2014-15 RDHS used a two-stage sample design to get a national representative sample. The first steps consisted of identification of 492 villages that were clustered proportionally into village size. The second sampling phase consisted of comprehensive mapping and listing of households in selected villages. Identified households provided a mapping frame in aiding the selection of the second sample. Systematic selection of households was done from the list to participate in the survey .[12] From all 492 villages surveyed. Of 12,793 households were selected and 12,717 households were identified as occupied during the survey period. Among the selected households, 12,699 households completed the questionnaire. In the 12,699 households surveyed, 13,564 women age 15-49 were identified as being eligible for the individual interview; interviews were completed with 13,497 of these women. We used a sample of 7,558 children whose information was collected and available in the Kid Record dataset (RWKR7OFL). The Kids Record dataset was considered because it holds child and maternal information that is relevant to this study.[11]

\section{Data collection tools}

This study used a secondary data analysis of the data that was collected by the Rwanda demographic and health survey 2014-15.[11] The survey used the Household Questionnaire, the Woman's Questionnaire, and the Man's Questionnaire. These questionnaires were adapted from the questionnaires developed by the worldwide DHS Program. Different stakeholders from governmental ministries and agencies, nongovernmental and international donors participated in adaptation of the questionnaires. The questionnaires were translated from English into Kinyarwanda. 


\section{Data analysis}

The analysis was performed using Stata13. Bivariate analysis was performed with was used chisquare tests to compare each risk factor between the groups of children who had diarrhea and those reported not to have diarrhea during the two weeks preceding the survey. Multivariate analysis was conducted to determine the relationship between selected environmental and nutritional factors with diarrhea has been estimated using binary logistic regression model. Odds ratio with corresponding 95\% confidence interval (CI) was used to quantify the strength of association.

\section{Ethical considerations}

The present study used a secondary data analysis of the data from the Rwanda
Demographic Health Survey. The ethical clearance was obtained from the Rwanda National Ethic Committee (RNEC). Confidentiality and privacy were ensured during the survey data collection and only codes were used for the recording of data and no names of respondent were used.

\section{Results}

\section{Sociodemographic characteristics of respondents}

Table 1 shows that male children were $55.1 \%$, all children were almost equally distributed into five age categories with age difference of 12 months. $55.9 \%$ mothers were aged 25-34 years.

Table 1. Sociodemographic characteristics of respondents $(N=7558)$

\begin{tabular}{lll}
\hline Variable & Frequency & Percentage (\%) \\
\hline Child age in months & & \\
$>12$ & 1617 & 21.39 \\
$12-24$ & 1537 & 20.34 \\
$24-36$ & 1533 & 20.28 \\
$36-48$ & 1584 & 20.96 \\
$48-60$ & 1287 & 17.03 \\
Sex of child & & \\
Male & 3810 & 50.41 \\
Female & 3748 & 49.59 \\
Mother's age in years & & \\
15-24 & 1460 & 19.32 \\
$25-34$ & 4232 & 55.99 \\
$35-44$ & 1727 & 22.85 \\
$45-55$ & 139 & 1.84 \\
\hline
\end{tabular}




\begin{tabular}{lll} 
Wealth index & & \\
Poorest & 1796 & 23.76 \\
Poorer & 1581 & 20.92 \\
Middle & 1427 & 18.88 \\
Richer & 1288 & 17.04 \\
Richest & 1466 & 19.4 \\
Type of place of residence & & \\
Urban & 1671 & 22.11 \\
Rural & 5887 & 77.89 \\
\hline
\end{tabular}

Nutritional factors associated with under five child diarrhea

Table 2 shows that breastfeeding and duration of breastfeeding were strongly associated with child diarrhea with $\mathrm{P}$-value $=0.001$. Other factors like receiving vitamin $\mathrm{A}$, feeding the child any fruit rich in vitamin $\mathrm{A}$, or getting ion tables during pregnancy were not linked with child diarrhea.

Table 2. Bivariate analysis of nutritional factors associated with under five child diarrhea

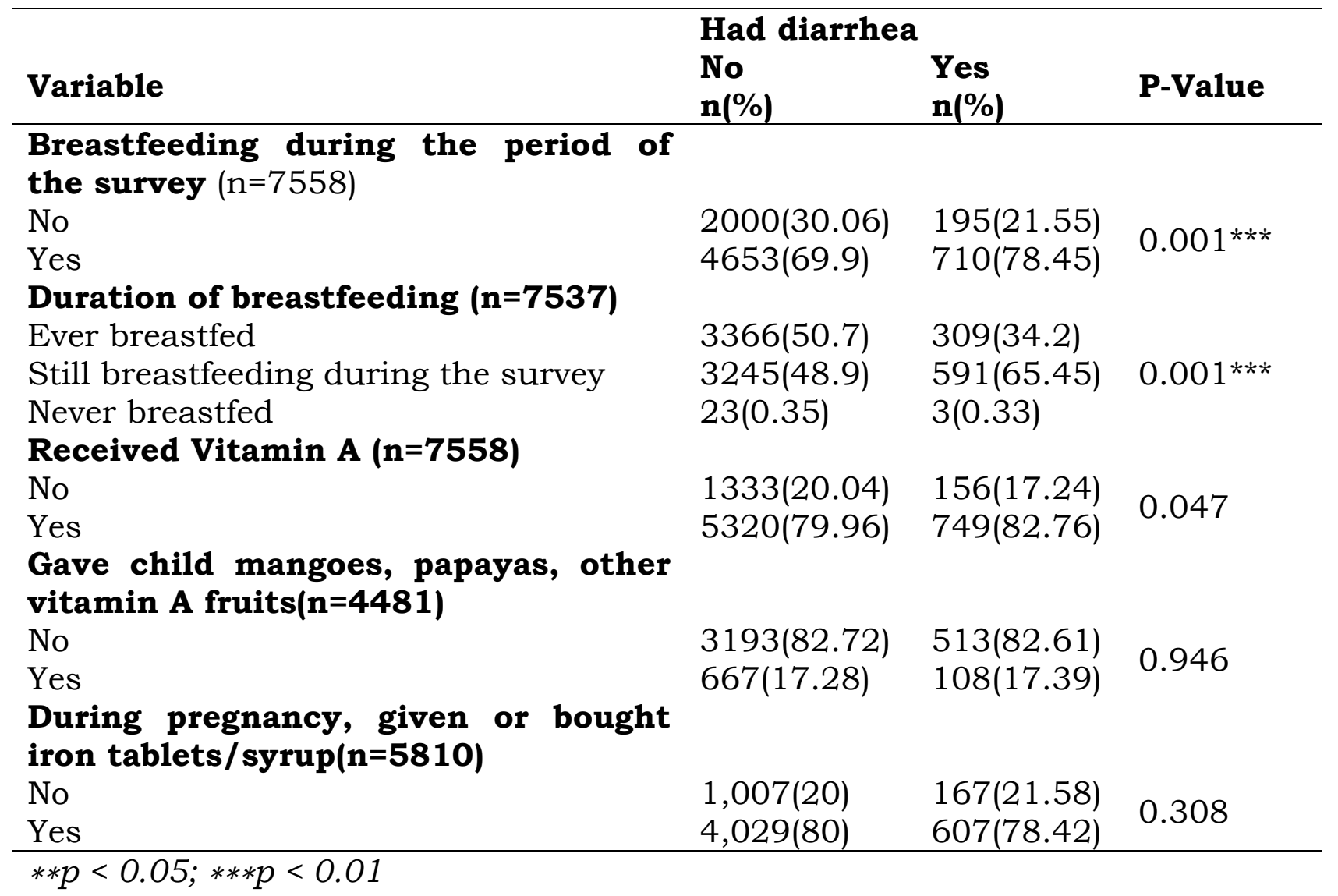




\section{Environmental factors associated with under five child diarrhea}

All selected environmental factors for diarrhea in this study associated with under five child diarrhea as shown in Table 4. The source of drinking water, the types of toilet facility, sharing toilet facilities with other households, and place of residence are significantly associated with child diarrhea. Pvalue $=0.001, \mathrm{P}$-value $=0.007$ and $\mathrm{P}$-value $=0.006$ respectively. Time spent to get to water source and are also associated with child diarrhea. P-value= 0.026

Table 3. Bivariate analysis of environmental factors associated with under five child diarrhea

\begin{tabular}{|c|c|c|c|}
\hline Variable & $\begin{array}{l}\text { Had diarrhea } \\
\text { No } \\
\text { n(\%) }\end{array}$ & $\begin{array}{l}\text { Yes } \\
\text { n(\%) }\end{array}$ & P-Value \\
\hline \multicolumn{4}{|c|}{ Type of place of residence $(n=7558)$} \\
\hline Urban & $1503(22.59)$ & $168(18.56)$ & \multirow{2}{*}{$0.006^{* * *}$} \\
\hline Rural & $5150(77.41)$ & $737(81.44)$ & \\
\hline \multicolumn{4}{|c|}{ Source of drinking water $(n=7557)$} \\
\hline Piped into dwelling & $44(0.66)$ & $7(0.77)$ & \multirow{13}{*}{$0.001^{* * *}$} \\
\hline Piped to yard/plot & $592(8.9)$ & $41(4.53)$ & \\
\hline Public tap/standpipe & $1823(27.41)$ & $262(28.95)$ & \\
\hline Tube well or borehole & $87(1.31)$ & $23(2.54)$ & \\
\hline Protected well & $121(1.82)$ & $27(2.98)$ & \\
\hline Unprotected well & $117(1.76)$ & $16(1.77)$ & \\
\hline Protected spring & $2026(30.46)$ & $267(29.5)$ & \\
\hline Unprotected spring & $958(14.4)$ & $122(13.48)$ & \\
\hline Surface water & 736(11.06) & $116(12.82)$ & \\
\hline Rainwater & $56(0.84)$ & $4(0.44)$ & \\
\hline Cart with small tank & $2(0.03)$ & $0(0)$ & \\
\hline Other & $1(0.02)$ & $0(0)$ & \\
\hline Not a de jure resident & $89(1.34)$ & $20(2.21)$ & \\
\hline \multicolumn{4}{|c|}{ Time (in hour) to get to water source $(n=6675)$} \\
\hline$<1$ & $5495(94.04)$ & 773(92.91) & \multirow{4}{*}{$0.026^{* *}$} \\
\hline $1-2$ & $320(5.48)$ & $52(6.25)$ & \\
\hline $2-3$ & $27(0.46)$ & $5(0.6)$ & \\
\hline $3-4$ & $1(0.02)$ & $2(0.24)$ & \\
\hline \multicolumn{4}{|c|}{ Type of toilet facility $(n=7551)$} \\
\hline Flush to piped sewer & $94(1.41)$ & $3(0.33)$ & \multirow{6}{*}{$0.001^{* * *}$} \\
\hline Flush to septic tank & $15(0.23)$ & $0(0)$ & \\
\hline Flush to pit latrine & $32(0.48)$ & $1(0.11)$ & \\
\hline Flush to somewhere else & 19(0.29) & $3(0.33)$ & \\
\hline Flush, don't know where & $5(0.08)$ & $0(0)$ & \\
\hline Ventilated improved pit & $325(4.89)$ & $48(5.3)$ & \\
\hline
\end{tabular}




\begin{tabular}{|c|c|c|c|c|c|}
\hline Pit latrine with slab & & & 4189(63.03) & $504(55.69)$ & \\
\hline Pit latrine without slab & & & $1625(24.45)$ & $262(28.95)$ & \\
\hline No facility/bush/field & & & $197(2.96)$ & $52(5.75)$ & \\
\hline Composting toilet & & & $46(0.69)$ & $10(1.1)$ & \\
\hline Other & & & $10(0.15)$ & $2(0.22)$ & \\
\hline Not a de jure resident & & & $89(1.34)$ & $20(2.21)$ & \\
\hline $\begin{array}{l}\text { Toilet facilities shared } \\
\text { households(n=7309) }\end{array}$ & with & other & & & \\
\hline No & & & 4949(76.66) & $618(72.45)$ & \\
\hline Yes & & & $1418(21.96)$ & $215(25.21)$ & $0.007^{* * *}$ \\
\hline Not a de jure resident & & & $89(1.38)$ & $20(2.34)$ & \\
\hline
\end{tabular}

$* * p<0.05 ; * * * p<0.01$

Multivariate logistic regression model for factors associated with child diarrhea

Of all factors that showed association with child diarrhea bivariate analysis, only two factors remain consistent. Those are the source of drinking water with OR: 1.8, CI [1.06-3.01], P-value=0.029; and sharing toilet facility with other households OR: 1.3 CI [1.04-1.53], P-value=0.019

Table 4. Multivariate logistic regression analysis of nutritional and environmental factors for child diarrhea






\begin{tabular}{llll}
\hline Cart with small tank & 1.00 & & \\
$\begin{array}{l}\text { Other } \\
\text { Time to get to water source }(<\mathbf{1} \text { hour) }\end{array}$ & 1.00 & & \\
$1-2$ & 1.13 & {$[0.81-1.57]$} & 0.482 \\
$2-3$ & 1.62 & {$[0.60-4.38]$} & 0.345 \\
$3-4$ & 7.77 & {$[0.52-115.61]$} & 0.137
\end{tabular}

Type of toilet facility(flush to piped sewer system)

Flush to septic tank $\quad 1.00$

Flush to pit latrine $\quad 1.00$

$\begin{array}{llll}\text { Flush to somewhere else } & 1.31 & {[0.14-11.98]} & 0.812\end{array}$

$\begin{array}{llll}\text { Ventilated improved pit latrine } & 1.15 & {[0.23-5.72]} & 0.867\end{array}$

$\begin{array}{llll}\text { Pit latrine with slab } & 0.85 & {[0.18-4.11]} & 0.842\end{array}$

$\begin{array}{llll}\text { Pit latrine without slab/open pit } & 1.02 & {[0.21-4.92]} & 0.983\end{array}$

Composting toilet $\quad 1.00$

Other 1.00

[0.17-5.67] 0.996

Not sharing toilet facilities with other households

Toilet facilities shared with other households

$* * p<0.05 ; * * * p<0.01$

1.2

households) were consistently

Discussion

associated with under five child diarrhea.

This study investigated the nutritional and environmental determinants of diarrheal diseases among children under-five years. In 7558 children sampled, $12 \%$ had diarrhea within two weeks preceding the data collection for the Rwanda demographic and health survey.[11]

The overall patterns in the associations between nutritional, and environmental factors with diarrhea in under-five observed in the bivariate and multivariate analysis. Multivariate regression analysis shows that two environmental factors (using borehole water source and shared toilet facilities with other

Consistent with other studies, the quality of household drinking water has been linked to the quality of life among populations; and using unimproved water causes various diseases, including diarrhea.[13-15] Borehole waters are possibly not treated before usage while it is a reservoir of waterborne pathogenic organisms and causes enteric diseases including diarrhea. A study conducted in Nigeria on bacteriological analysis of borehole water showed that the water from the boreholes do not meet the WHO standards for drinking water.[15] The research evidence emphasize on the importance and the necessity of boiling and 
filtration of water from borehole before consumption to prevent the spread of water borne diseases diarrhea included. For example, Okolo and his colleagues conducted a comparative analysis of three borehole water sources from Nigeria. They analysed the quality of borehole water samples from three locations and concluded that borehole water was contaminated. They therefore recommended treatment of borehole water before consumption to prevent the spread of water borne diseases.[16,17] This study revealed that sharing toilets is associated with diarrhea among children under five years old. A study conducted in Indonesia on the relationship of the presence of a household improved latrine with Diarrhea confirmed that the lack of a household improved latrine is associated with diarrhea and underfive child mortality. Fuller et $A l$. conducted a study on shared sanitation and the prevalence of diarrhea in young children from 51 low and middle income countries, between the year 2001-2011. In their findings, they came to the conclusion that the households that share toilet facility are likely to experience the higher prevalence of diarrhea than those owning their toilet facilities.[18] The health outcomes for the household members who use to share toilets include diarrhea or other faecal oral diseases. Children less than 5-year-old living in households sharing a toilet with one or more households, are more likely to experience moderate to severe diarrhea than children living in households with private sanitation. $[18,19]$

\section{Conclusion and recommendation}

The environmental factors including source of water and toilets facilities shared with neighbours are associated with diarrhea among children under five years of age. The study therefore recommends the provision of adequate portable water to the communities should be given a highest priority to prevent child morbidity caused by diarrhea. In addition, efforts from the community health clubs (CHCs) should be driven to the promotion and support of households' ownership and utilization of toilets and therefore cease toilet sharing.

\section{Conflict of interest}

The authors declare that there is no conflict of interest related to this manuscript.

\section{Authors' contributions}

JCI contributed to all aspects of the work. ER and OM contributed to the scientific review of the manuscript and provided their intellectual inputs.

This article is published open access under the Creative Commons Attribution-NonCommercial NoDerivatives (CC BYNC-ND4.0). People can copy and redistribute the article only for noncommercial purposes and as long as they give appropriate credit to the authors. They cannot distribute any modified material obtained by remixing, transforming or building upon this article. See https://creativecommons.org/licenses/by-ncnd/4.0/ 


\section{References}

1. WHO. Diarrhoeal disease. WHO Heal. Top. sheets. 2017.

2. WHO. Diarrhoeal disease fact sheet. World Health Organization; 2017;

3. Clasen $\mathrm{TF}$, Alexander KT, Sinclair D, Boisson S, Peletz $\mathrm{R}$, Chang $\mathrm{HH}$, et al. Interventions to improve water quality for preventing diarrhoea.

Cochrane database Syst Rev. WileyBlackwell; 2015;CD004794.

4. Fischer Walker CL, Rudan I, Liu L, Nair H, Theodoratou E, Bhutta ZA, et al. Global burden of childhood pneumonia and diarrhoea. Lancet. 2013;381.

5. Farthing $M$, Salam MA, Lindberg G, Dite P, Khalif I, Salazar-Lindo E, et al. Acute diarrhea in adults and children: A global perspective. J. Clin. Gastroenterol. 2013. p. 1220.

6. The World Bank Group. Disease Control Priorities, Third Edition (Volume 2): Reproductive, Maternal, Newborn, and Child Health.
Dis. Control Priorities, Third Ed. (Volume 2) Reprod. Matern. Newborn, Child Heal. The World Bank; 2016.

7. WHO/UNICEF. Ending preventable child deaths from pneumonia and diarrhoea by 2025. The integrated Global Action Plan for Pneumonia and Diarrhoea (GAPPD). 2013.

8. Chola L, Michalow J, Tugendhaft A, Hofman K. No Title. BioMed Central; 2015;15:394.

9. Liu L, Oza S, Hogan D, Perin J, Rudan I, Lawn JE, et al. Global, regional, and national causes of child mortality in 2000-13, with projections to inform post-2015 priorities: An updated systematic analysis. Lancet. Elsevier Ltd; 2015;385:430-40.

10. Murray CJL, Vos T, Lozano R, Naghavi $M$, Flaxman AD, Michaud C, et al. Disabilityadjusted life years (DALYs) for 291 diseases and injuries in 21 regions, 1990-2010: A systematic analysis for the Global Burden of Disease Study 2010. Lancet. 2012;380:2197-223.

11. NISR. Demographic and Health Survey (2014/15). 2015. 
12. National Institute of Statistics of Rwanda. Rwanda 2014-15 Demographic and Health Survey. Key Findings. $2015 ; 24$.

13. Cha S, Cho Y, Kim SJ, Lee $\mathrm{Y}$, Choi S, Asuming $\mathrm{P}$, et al. Cost-benefit analysis of water source improvements through borehole drilling or rehabilitation: an empirical study based on a cluster randomized controlled trial in the Volta Region, Ghana. Glob Health Action. Taylor and Francis Ltd.; 2018;11:1523303.

14. Ibe SN, Okplenye JI. Bacteriological analysis of borehole water in Uli, Nigeria. African J Appl Zool Environ Biol. African Journals Online (AJOL); 2008;7:116-9.

15. Nnama Jude-anthony O, Chibuogwu Orji J. Enteric pathogens and diarrhea disease potentials of water sources in Ahiazu Mbaise, Eastern Nigeria. J Public Heal Epidemiol. 2012;4:3943.

16. Charity, Esomonu Onyenonachi AOC, Emeka and IC. Enteric pathogens and diarrhea disease potentials of water sources in Ahiazu Mbaise, Eastern Nigeria. J Public Heal Epidemiol. 2012;4:39-43.

17. Okoro N. OEO, O OP. Comparative Analysis of Three Borehole Water Sources in Nsukka Urban Area, Enugu State, Nigeria. Resour Environ. 2017;7:110-4.

18. Fuller JA, Clasen T, Heijnen $M$, Eisenberg JNS. Shared sanitation and the prevalence of diarrhea in young children: Evidence from 51 countries, 20012011. Am J Trop Med Hyg. American Society of Tropical Medicine and Hygiene; 2014;91:173-80.

19. Hailemichael Bizuneh FG, Meressa B, , Yonatan Tegene and $\mathrm{GW}$, Bizuneh $\mathrm{H}$, Getnet F, Meressa B, et al. No Title. BMC Pediatr. BioMed Central Ltd.; 2017;17:1-7. 